ARTICLE

https://doi.org/10.1038/s41467-018-08117-6

\title{
Unusual synergistic effect in layered Ruddlesden - Popper oxide enables ultrafast hydrogen evolution
}

\author{
Yinlong Zhu', Hassan A. Tahini (1) 2, Zhiwei Hu ${ }^{3}$, Jie Dai ${ }^{1}$, Yubo Chen ${ }^{4}$, Hainan Sun', \\ Wei Zhou (1) ${ }^{1}$, Meilin Liu (1) ${ }^{5}$, Sean C. Smith², Huanting Wang ${ }^{6} \&$ Zongping Shao ${ }^{1,7}$
}

Efficient electrocatalysts for hydrogen evolution reaction are key to realize clean hydrogen production through water splitting. As an important family of functional materials, transition metal oxides are generally believed inactive towards hydrogen evolution reaction, although many of them show high activity for oxygen evolution reaction. Here we report the remarkable electrocatalytic activity for hydrogen evolution reaction of a layered metal oxide, Ruddlesden-Popper-type $\mathrm{Sr}_{2} \mathrm{RuO}_{4}$ with alternative perovskite layer and rock-salt $\mathrm{SrO}$ layer, in an alkaline solution, which is comparable to those of the best electrocatalysts ever reported. By theoretical calculations, such excellent activity is attributed mainly to an unusual synergistic effect in the layered structure, whereby the (001) SrO-terminated surface cleaved in rock-salt layer facilitates a barrier-free water dissociation while the active apical oxygen site in perovskite layer promotes favorable hydrogen adsorption and evolution. Moreover, the activity of such layered oxide can be further improved by electrochemistry-induced activation.

\footnotetext{
${ }^{1}$ Jiangsu National Synergetic Innovation Center for Advanced Materials (SICAM), State Key Laboratory of Materials-Oriented Chemical Engineering, College of Chemical Engineering, Nanjing Tech University, No. 5 Xin Mofan Road, 210009 Nanjing, P.R. China. ${ }^{2}$ Department of Applied Mathematics, Research School of Physics and Engineering, Australian National University, Canberra, ACT 0200, Australia. ${ }^{3}$ Max Planck Institute for Chemical Physics of Solids, Nothnitzer Strasse 40, 01187 Dresden, Germany. ${ }^{4}$ School of Material Science and Engineering, Nanyang Technological University, 50 Nanyang Avenue, Singapore 639798, Singapore. ${ }^{5}$ Center for Innovative Fuel Cell and Battery Technologies, School of Materials Science and Engineering, Georgia Institute of Technology, Atlanta, GA 30332-0245, USA. ${ }^{6}$ Department of Chemical Engineering, Monash University, Clayton, VIC 3800 , Australia. ${ }^{7}$ Department of Chemical Engineering, Curtin University, Perth, WA 6845, Australia. Correspondence and requests for materials should be addressed to

W.Z. (email: zhouwei1982@njtech.edu.cn) or to Z.S. (email: shaozp@njtech.edu.cn)
} 
W ith the accelerating depletion of fossil fuels and associated negative environmental impact from their excessive use, clean and renewable energy alternatives have been receiving great demand during the past years ${ }^{1}$. Hydrogen $\left(\mathrm{H}_{2}\right)$, which possesses the highest gravimetric energy density and zero-carbon nature, is regarded as a promising energy carrier or fuel to replace fossil fuels ${ }^{2}$. Globally, hydrogen production mainly comes from the industrial steam reforming with converting natural gas and water into carbon dioxide and hydrogen, whereas the energy inefficiency of the conversion process and the existence of carbon-containing residues can lead to high costs and low purity of the hydrogen products ${ }^{3}$. To address this, an alternative technique to produce hydrogen is via electrochemical water splitting, which benefits from unlimited water resources, stable output, high product purity, feasibility of large-scale production, and the capability of integrating renewable energy as power source 4 . However, the rate of the hydrogen evolution reaction (HER) in water splitting is relatively sluggish and requires an efficient electrocatalyst to promote the HER process $^{5}$. Notably, the HER kinetics for most catalysts in alkaline solutions is at least two orders of magnitude slower than in acidic ones due to the extra water dissociation step ${ }^{6}$. Although platinum (Pt) metal demonstrates favorable activity for HER in both acidic and alkaline media, the scarcity, high cost and poor stability severely limit the viability for commercial applications ${ }^{5}$. Extensive efforts have been devoted to the development of highly active and durable Pt-free HER catalysts in alkaline solutions to achieve economical hydrogen production.

As a large and important class of inorganic compounds, transition metal oxides (TMOs) have attracted great interest in many fields (e.g., efficient oxygen evolution reaction (OER) catalysts in alkaline solutions) by virtue of the merits of their stability, abundance, accessibility, and environmental friendliness ${ }^{7,8}$. However, bulk TMOs are generally deemed as inactive materials for alkaline HER because of poor electrical conductivity and inappropriate hydrogen adsorption energy ${ }^{9}, 10$. For example, ruthenium dioxide $\left(\mathrm{RuO}_{2}\right)$, a state-of-the-art OER electrocatalyst, was found to be only moderately active for $\operatorname{HER}^{11,12}$.

To date, several important trials have been conducted to develop oxides that can serve as efficient HER electrocatalysts. Since the mass activity of a catalyst is determined by both the intrinsic activity and the amount of active sites, increasing the amount of active sites is a direct way to increase the mass activity. Luo et al. synthesized a nonstoichiometric and mesoporous $\mathrm{MoO}_{3-x}$ with high surface area of $52 \mathrm{~m}^{2} \mathrm{~g}^{-1}$ via an inverse micelle-template method $^{13}$, which shows favorable electrocatalytic activity for HER in an alkaline condition, achieving an overpotential of $138 \mathrm{mV}$ at $10 \mathrm{~mA} \mathrm{~cm}^{-2}$. Wang et al. fabricated some TMO nanoparticles with diameters of $2-5 \mathrm{~nm}$ using lithium-induced electrochemical conversion reactions, demonstrating excellent activity for OER and favorable activity for $\mathrm{HER}^{14}$. To further increase the activity, Qiao et al. applied surface strain engineering strategy to alter the surface atom and electronic structure of nanostructured $\mathrm{CoO}$, thus enhancing the alkaline HER activity ${ }^{8}$. Despite these efforts, the HER activity of oxides in alkaline media, especially in bulk counterpart, remains much inferior to that of the benchmark Pt catalyst; also, the synthetic processes are complex, of low yield, and difficult for cost-effective and wide-scale fabrication. Therefore, simple and effective strategies are still needed for the development of metal oxide-based electrocatalysts with high intrinsic HER activity.

In addition to the simple TMOs, complex oxides containing more than one metal (e.g., perovskite oxides) have been the focus of numerous studies for various applications by virtue of their structural and compositional flexibility $15-18$. The multiple elements and variable structures of complex oxides can give rise to some unique bulk material properties (e.g., crystal, electronic and conductive properties), which then affect the surface properties of the oxides directly or indirectly, and consequently their electrocatalytic activities ${ }^{19,20}$. Thus, engineering the bulk structure can provide new opportunities to screen for superior catalysts.

Here we report our findings in rational design of a layered Ruddlesden-Popper (RP)-type oxide $\mathrm{Sr}_{2} \mathrm{RuO}_{4}$, derived from $\mathrm{RuO}_{2}$, demonstrating dramatically enhanced electrocatalytic activity for HER. Although the specific surface area of bulk $\mathrm{Sr}_{2} \mathrm{RuO}_{4}$ is relatively low $\left(\sim 1.4 \mathrm{~m}^{2} \mathrm{~g}^{-1}\right)$, the turnover frequency (TOF) for HER is $\sim 10$ times higher that of $\mathrm{RuO}_{2}$. When evaluated in $1 \mathrm{M} \mathrm{KOH}$ solution, the outstanding HER activity is reflected by an overpotential of only $61 \mathrm{mV}$ at $10 \mathrm{~mA} \mathrm{~cm}^{-2}$ and a low Tafel slope of $51 \mathrm{mV} \mathrm{dec}^{-1}$, comparable to those of the commercial Pt/ C catalyst and surpassing all metal oxides and other well-known Pt-free catalysts reported to date. Theoretical and experimental analyses reveal that an unusual synergistic effect in the layered RP structure possibly contributes to the HER activity of $\mathrm{Sr}_{2} \mathrm{RuO}_{4}$ : SrO-terminated surface cleaved in rock-salt layer promotes water dissociation without a barrier while the active apical oxygen site in the perovskite layer enables favorable hydrogen adsorption and evolution. Besides, the HER activity of $\mathrm{Sr}_{2} \mathrm{RuO}_{4}$ can be further improved by the interface synergy between in situ formation of $\mathrm{Ru}$ nanoparticle and oxide substrate over the surface as well as incremental electrochemical surface area (ECSA) during electrochemistry-induced activation process. The design strategy of the layered $\mathrm{RP} \mathrm{Sr}_{2} \mathrm{RuO}_{4}$ oxide and the derived synergistic effect for HER catalysis may be applicable to knowledge-based design of more efficient nonprecious electrocatalysts.

\section{Results}

Bulk structure characterization. Since $\mathrm{RuO}_{2}$ has only modest activity for HER in the alkaline solution, the electrocatalytic activity of several Ru-based oxides with different crystal structures was characterized to determine the effect of crystal structure on activity. Figure $1 \mathrm{a}-\mathrm{c}$ shows the $\mathrm{X}$-ray diffraction (XRD) patterns of $\mathrm{RuO}_{2}, \mathrm{SrRuO}_{3}$, and $\mathrm{Sr}_{2} \mathrm{RuO}_{4}$ powders synthesized using a solid-state reaction process. All diffraction peaks of the three oxide samples match well with those of the corresponding standard patterns (JCPDS No. 71-2273, 89-5713, and 81-1978, respectively), indicating their phase purity without observable impurities. This is also confirmed by the Rietveld refinement of the XRD patterns (Supplementary Fig. 1); the space group is $P 42 / m n m$ for $\mathrm{RuO}_{2}$, Pnma for $\mathrm{SrRuO}_{3}$, and $I 4 / \mathrm{mmm}$ for $\mathrm{Sr}_{2} \mathrm{RuO}_{4}$. The local crystal structure and overall network of the $\left[\mathrm{RuO}_{6}\right]$ octahedra in the three structures are schematically shown in inserted Fig. 1a-c based on the Rietveld analysis along with the detailed structure parameters (Supplementary Table 1). Particularly, $\mathrm{Sr}_{2} \mathrm{RuO}_{4}$ oxide crystallizes in the $\mathrm{K}_{2} \mathrm{NiF}_{4}$-type structure with layers of corner-linked $\left[\mathrm{RuO}_{6}\right]$ octahedra separated by $[\mathrm{SrO}]$ rock-salt layers along the $c$ direction, which is schematically illustrated in Fig. 1d. Actually, $\mathrm{Sr}_{2} \mathrm{RuO}_{4}$ belongs to the so-called RP series with the formula $\mathrm{Sr}_{n}$ ${ }_{+1} \mathrm{Ru}_{n} \mathrm{O}_{3 n+1}{ }^{21}$. These strontium ruthenates consist of alternative perovskite $\mathrm{SrRuO}_{3}$ layer and $\mathrm{SrO}$ rock-salt layer. The layered RP crystal structure of $\mathrm{Sr}_{2} \mathrm{RuO}_{4}$ is further confirmed by the selected-area electron-diffraction (SAED) pattern along the [010] zone axes and the corresponding high-resolution transmission electron microscopy (HRTEM) image. The SAED pattern in Fig. 1e and fast Fourier transform (FFT) images insert in Fig. If clearly reflect the tetragonally arranged diffraction spots of [010] zone axes. In addition, a lattice fringe with lattice spacing of $0.64 \mathrm{~nm}$ was observed in the HRTEM image (Fig. 1f), corresponding to the (002) plane of $\mathrm{Sr}_{2} \mathrm{RuO}_{4}$ oxide. X-ray absorption spectroscopy (XAS) technique was 
a

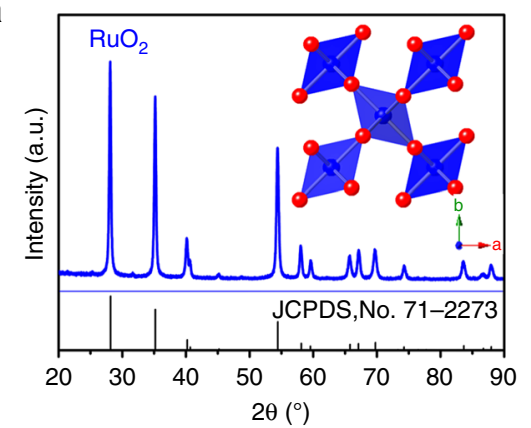

b

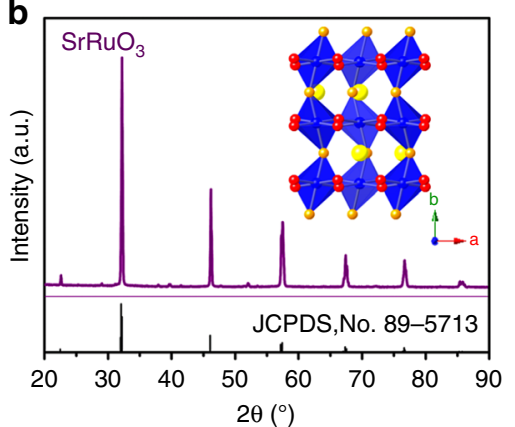

c

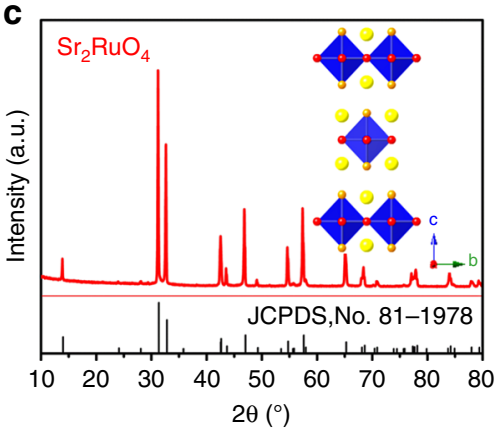

d

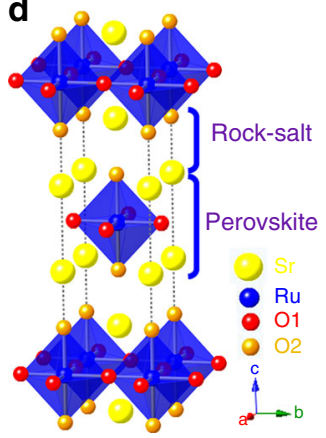

e

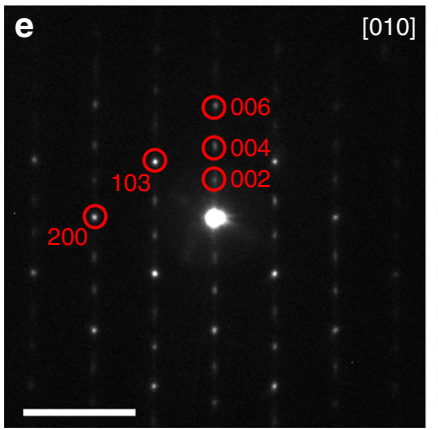

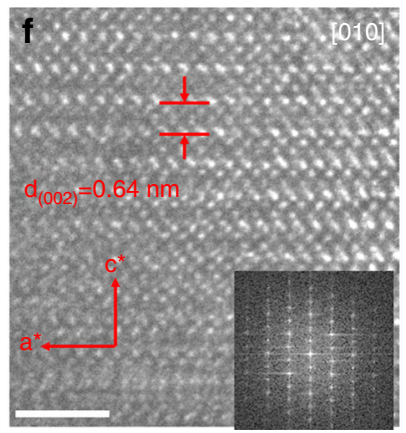

g

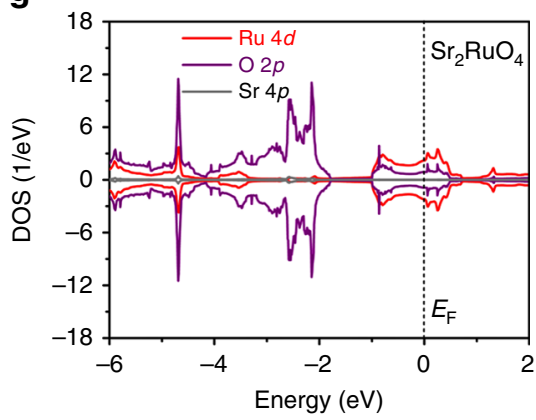

Fig. 1 Bulk structure characterization. XRD patterns of $\mathbf{a} \mathrm{RuO}_{2}$, b SrRuO 3 , and $\mathbf{c} \mathrm{Sr}_{2} \mathrm{RuO}_{4}$. Insert shows the local crystal structure of respective oxide. Color code: $\mathrm{Sr}$ (yellow), $\mathrm{Ru}$ (blue), and $\mathrm{O}$ (red and orange). d Schematic presentation of the layered RP structure of $\mathrm{Sr}_{2} \mathrm{RuO}_{4}$. e SAED pattern and the corresponding HRTEM images (f) along the [010] zone axes for $\mathrm{Sr}_{2} \mathrm{RuO}_{4}$. Insert is the FFT. $\mathbf{g}$ DFT calculation of the DOS of $\mathrm{Sr}_{2} \mathrm{RuO}_{4}$. Scale bar in (e) is 5 $\mathrm{nm}^{-1}$ and in (f) is $2 \mathrm{~nm}$

further performed to analyze the oxidation state of $\mathrm{Ru}$ in the $\mathrm{Sr}_{2} \mathrm{RuO}_{4}$. Supplementary Fig. 2 shows the $\mathrm{Ru}-L_{2,3}$ XAS spectra of the as-synthesized $\mathrm{Sr}_{2} \mathrm{RuO}_{4}$ sample and the reference samples with different valence states of $\mathrm{Ru}$. The $\mathrm{Ru}-L_{2,3}$ spectra of the as-synthesized $\mathrm{Sr}_{2} \mathrm{RuO}_{4}$ sample is completely the same as the reference $\mathrm{Sr}_{2} \mathrm{RuO}_{4}$ (including spectra shape and peak position), suggesting the character of stoichiometry and only $\mathrm{Ru}^{4+}$ in the as-synthesized $\mathrm{Sr}_{2} \mathrm{RuO}_{4}$ sample.

The morphologies of $\mathrm{RuO}_{2}, \mathrm{SrRuO}_{3}$, and $\mathrm{Sr}_{2} \mathrm{RuO}_{4}$ powders were examined by scanning electron microscopy (SEM) as displayed in Supplementary Fig. 3. Micrometer-sized particles were observed, suggesting the bulk nature of the as-synthesized $\mathrm{SrRuO}_{3}$ and $\mathrm{Sr}_{2} \mathrm{RuO}_{4}$ oxides by solid-state reaction method. The $\mathrm{RuO}_{2}$ appears to have smaller particle size than $\mathrm{SrRuO}_{3}$ and $\mathrm{Sr}_{2} \mathrm{RuO}_{4}$, and accordingly have larger surface areas as calculated from the Brunauer-Emmett-Teller (BET) measurements (Supplementary Fig. 4).

We also use density functional theory (DFT) calculations to unveil the electronic structures of $\mathrm{RuO}_{2}, \mathrm{SrRuO}_{3}$, and $\mathrm{Sr}_{2} \mathrm{RuO}_{4}$ by calculating the density of states (DOS) (Fig. $1 \mathrm{~g}$ and Supplementary Fig. 5). It can be found clearly that the DOS profiles of Ru and $O$ change significantly among the three oxides, accordingly having different electronic structures. Nevertheless, the three oxides all present a typical metallic behavior with predominantly $\mathrm{Ru} 4 d$ and $\mathrm{O} 2 p$ orbital crossing the Fermi level, which is highly beneficial to electrocatalysis due to high electronic conductivity ${ }^{10}$. Based on the above combined analysis, the $\mathrm{Sr}_{2} \mathrm{RuO}_{4}$ exhibits distinctive structural features (e.g., alternative layers, $\left[\mathrm{RuO}_{6}\right]$ coordination geometry, $\mathrm{Ru}-\mathrm{O}$ bond length, states near Fermi level) relative to $\mathrm{RuO}_{2}$ and $\mathrm{SrRuO}_{3}$, although they have the same oxidation state of $\mathrm{Ru}^{4+}$ and similar morphology. These structural features in $\mathrm{Sr}_{2} \mathrm{RuO}_{4}$ are the key factors for enhancing the HER activity, as to be discussed below.
Comprehensive evaluation of HER activity. To evaluate the electrocatalytic HER activity of $\mathrm{RuO}_{2}, \mathrm{SrRuO}_{3}$, and $\mathrm{Sr}_{2} \mathrm{RuO}_{4}$ oxides with different crystal structures in alkaline media, an electrochemical cell with a three-electrode configuration in an Arsaturated $1 \mathrm{M} \mathrm{KOH}$ solution was used. Unless indicated otherwise, all potentials in this study were referenced to a reversible hydrogen electrode (RHE, see Supplementary Fig. 6 for RHE calibration) and $i R$-corrected to eliminate the ohmic potential drop across the electrolyte. Figure 2a shows the polarization curves gained from linear sweep voltammetry at a scan rate of 5 $\mathrm{mV} \mathrm{s}^{-1}$. $\mathrm{Sr}_{2} \mathrm{RuO}_{4}$ can effectively catalyze alkaline HER with an extremely low onset overpotential (defined here as the overpotential at $1 \mathrm{~mA} \mathrm{~cm}^{-2}$ ) of $\sim 3 \mathrm{mV}$; as a comparison, $\mathrm{RuO}_{2}$ and $\mathrm{SrRuO}_{3}$ show much larger onset potential of $\sim 46$ and $\sim 28 \mathrm{mV}$, respectively. It is also seen that the added conductive carbon, which is always identified as a conductive additive and support in oxide electrodes ${ }^{22-24}$, displays negligible HER activity (Supplementary Fig. 7). Besides, the $\mathrm{Sr}_{2} \mathrm{RuO}_{4}$ requires a small overpotential of $61 \mathrm{mV}$ to obtain a current density of $-10 \mathrm{~mA} \mathrm{~cm}^{-2}$, much lower than that of the $\mathrm{RuO}_{2}(95 \mathrm{mV})$ and $\mathrm{SrRuO}_{3}(101$ $\mathrm{mV}$ ) catalysts. The result suggests that the $\left[\mathrm{RuO}_{6}\right]$ octahedra layer in the $\mathrm{Sr}_{2} \mathrm{RuO}_{4}$ structure has much higher electrocatalytic activity for HER than those in the other two crystal structures.

To gain more insight into the electrochemical behavior of the electrocatalysts, polarizations in a broader range of overpotential were acquired and presented in Fig. 2b. In general, HER in an alkaline electrolyte includes two steps, i.e., electron-coupled water dissociation (the formation of $\mathrm{H}_{\mathrm{ad}}$ by the Volmer step) and the concomitant transformation of $\mathrm{H}_{\mathrm{ad}}$ into molecular $\mathrm{H}_{2}$ (the Heyrovsky or Tafel step $)^{5,25}$. A Tafel slope for the Volmer, Heyrovsky, and Tafel step, as the rate-determining step for HER, is expected to be $\sim 120, \sim 40$, and $\sim 30 \mathrm{mV} \mathrm{dec}^{-1}$ respectively $y^{5,25}$. $\mathrm{Sr}_{2} \mathrm{RuO}_{4}$ yields a Tafel slope of $51 \mathrm{mV} \mathrm{dec}-1$, which is close to the 

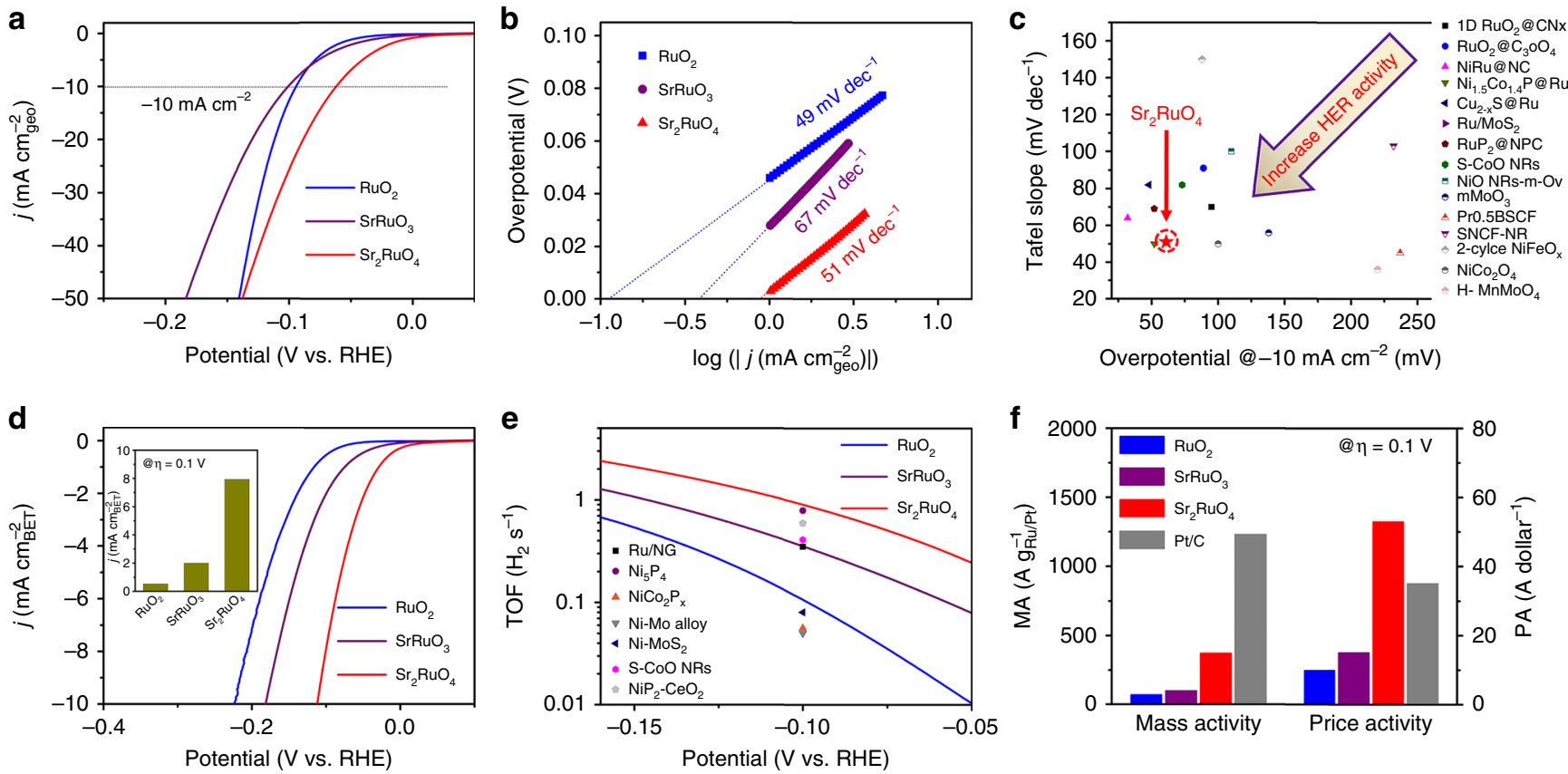

Fig. 2 Electrocatalytic HER activity. a Polarization curves and corresponding $\mathbf{b}$ Tafel plots of $\mathrm{RuO}_{2}, \mathrm{SrRuO}_{3}$, and $\mathrm{Sr}_{2} \mathrm{RuO}_{4}$ catalysts in an $\mathrm{Ar}$-saturated $1 \mathrm{M}$ $\mathrm{KOH}$ solution. Scan rate, $5 \mathrm{mV} \mathrm{s}^{-1}$. c Alkaline HER activity comparison graph showing the Tafel slope with overpotential@-10 mA cm ${ }^{-2}$. d Specific activity normalized to BET surface area of $\mathrm{RuO}_{2}, \mathrm{SrRuO}_{3}$, and $\mathrm{Sr}_{2} \mathrm{RuO}_{4}$ catalysts as a function of potential. Inset: specific activity at the overpotential of $\eta=0.1 \mathrm{~V}$. e The relationship between TOF and the tested potentials for $\mathrm{RuO}_{2}, \mathrm{SrRuO}_{3}$, and $\mathrm{Sr}_{2} \mathrm{RuO}_{4}$ electrocatalysts in $1 \mathrm{M} \mathrm{KOH}$ solution. TOF values of some wellknown HER catalysts in the literature are also shown for comparison. $\mathbf{f}$ Mass activity (MA) and price activity $(\mathrm{PA})$ of $\mathrm{RuO}_{2}, \mathrm{SrRuO}_{3}, \mathrm{Sr}_{2} \mathrm{RuO}_{4}$ and $\mathrm{Pt} / \mathrm{C}$ at the overpotential of $\eta=0.1 \mathrm{~V}$

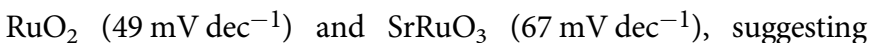
hydrogen evolution via Volmer-Heyrovsky mechanism in the alkaline electrolyte for all three oxides, and that the Heyrovsky step is the rate-limiting step. Also, small Tafel slope of $\mathrm{Sr}_{2} \mathrm{RuO}_{4}$ implies fast HER kinetics. Furthermore, the exchange current density $\left(j_{0}\right)$ was obtained from extrapolating the Tafel plots to zero overpotential. The $j_{0}$ is dependent sensitively on the nature of the catalyst material and determines the rate of the intrinsic electron transfer between the catalyst and the electrolyte solution ${ }^{26}$. The $j_{0}$ value of $\mathrm{Sr}_{2} \mathrm{RuO}_{4}$ is $0.898 \mathrm{~mA} \mathrm{~cm}^{-2}$, which is $\sim 8$-fold and $\sim 2$-fold higher than that of $\mathrm{RuO}_{2}\left(0.115 \mathrm{~mA} \mathrm{~cm}^{-2}\right)$ and $\mathrm{SrRuO}_{3}(0.409$ $\mathrm{mA} \mathrm{cm}{ }^{-2}$ ), respectively. As a whole, the high HER kinetic metrics (including the small overpotential, low Tafel slope, and high exchange current density) highlight the outstanding catalytic activity of $\mathrm{Sr}_{2} \mathrm{RuO}_{4}$ for HER in alkaline media, in particular by considering its small specific surface area $\left(1.4 \mathrm{~m}^{2} \mathrm{~g}^{-1}\right)$. Such excellent HER activity of $\mathrm{Sr}_{2} \mathrm{RuO}_{4}$ is superior to those of other metal oxides and Ru-based catalysts (Fig. 2c) as well as various well-known active Pt-free catalysts reported to date. A detailed HER activity comparison with previously reported representative HER catalysts, including metal/alloy, metal phosphides, metal sulfides, metal selenides, metal carbides, functional carbon and composites etc., demonstrates that $\mathrm{Sr}_{2} \mathrm{RuO}_{4}$ is among the most active HER catalyst in alkaline media (Supplementary Table 2).

It is well known that the overall catalytic activity of an electrocatalyst system is generally determined by two key factors: the intrinsic activity of each active site and the number of active sites ${ }^{27}$. To assess the intrinsic activity of $\mathrm{RuO}_{2}, \mathrm{SrRuO}_{3}$, and $\mathrm{Sr}_{2} \mathrm{RuO}_{4}$ oxides, it is necessary to eliminate the contribution derived from the surface areas and thereby calculate the specific activity (SA) normalized to the real oxide surface area or ECSA. The real oxide surface area and ECSA are estimated from the BET measurements (Supplementary Fig. 4$)$ and double-layer capacitance $\left(C_{\mathrm{dl}}\right)$ measurements (Supplementary Fig. 8), respectively. The $C_{\mathrm{dl}}$ obtained from a cyclic voltammetry (CV) method is expected to be linearly proportional to the $\mathrm{ECSA}^{5,25}$. As shown in Fig. $2 \mathrm{~d}$ and Supplementary Fig. 9, the SA of $\mathrm{Sr}_{2} \mathrm{RuO}_{4}$ is much higher than that of $\mathrm{RuO}_{2}$ and $\mathrm{SrRuO}_{3}$, regardless of the current densities normalized by the BET surface area or ECSA. For example, at $\eta=0.1 \mathrm{~V}$, the $\mathrm{Sr}_{2} \mathrm{RuO}_{4}$ delivers an SA of $7.93 \mathrm{~mA} \mathrm{~cm}^{-2}$ BET, which is $\sim 15$ and $\sim 4$ times higher than that for $\mathrm{RuO}_{2}$ and $\mathrm{SrRuO}_{3}$. The TOF, which is associated with the number of $\mathrm{H}_{2}$ molecules evolved per second per active site, is another important parameter that characterizes the intrinsic activity of an electrocatalyst ${ }^{28-30}$. In this work, TOF values were calculated according to a well-known method reported by the Jaramillo group (see the Supplementary Information for detailed calculations, Supplementary Fig. 10 and Supplementary Note 1) 29,30 . Figure 2e shows the TOF (per surface active $\mathrm{O}$ atom) versus potential plots of $\mathrm{RuO}_{2}, \mathrm{SrRuO}_{3}$, and $\mathrm{Sr}_{2} \mathrm{RuO}_{4}$ catalysts, and it reveals that the TOF values follows the order in the sequence of $\mathrm{Sr}_{2} \mathrm{RuO}_{4}>\mathrm{SrRuO}_{3}>\mathrm{RuO}_{2}$. Particularly, the $\mathrm{Sr}_{2} \mathrm{RuO}_{4}$ electrocatalyst delivers an extremely high TOF value of $0.90 \mathrm{~s}^{-1}$ at overpotential $(\eta)$ of $0.1 \mathrm{~V}$, which is evidently larger than that of some well-known HER catalysts in $1 \mathrm{M} \mathrm{KOH}$ solution, e.g., $\mathrm{Ru} / \mathrm{NG}\left(0.35 \mathrm{~s}^{-1}\right), \mathrm{Ni}_{5} \mathrm{P}_{4}$ $\left(0.79 \mathrm{~s}^{-1}\right), \mathrm{NiCo}_{2} \mathrm{P}_{x}\left(0.056 \mathrm{~s}^{-1}\right), \mathrm{Ni}-\mathrm{Mo}$ alloy $\left(0.05 \mathrm{~s}^{-1}\right), \mathrm{Ni}-\mathrm{MoS}_{2}$ $\left(0.08 \mathrm{~s}^{-1}\right)$, S-CoO NRs $\left(0.41 \mathrm{~s}^{-1}\right), \mathrm{NiP}_{2}-\mathrm{CeO}_{2}\left(0.593 \mathrm{~s}^{-1}\right)$ (Supplementary Table 3). According to the HER activities of $\mathrm{RuO}_{2}, \mathrm{SrRuO}_{3}$, and $\mathrm{Sr}_{2} \mathrm{RuO}_{4}$ summarized in Supplementary Table 4, the intrinsic

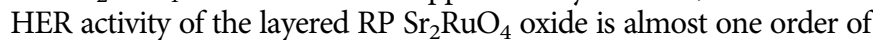
magnitude higher than that of the $\mathrm{RuO}_{2}$, yet the ruthenium content is much less, only $\sim 61 \mathrm{wt} \%$ of that in $\mathrm{RuO}_{2}$, producing the dual beneficial effects of activity enhancement and cost reduction simultaneously. The HER activity was further confirmed by the Faradaic efficiency, which is assessed by comparing the theoretical and detected volumes of generated gases during potentiostatic electrolysis experiments. As shown in Supplementary Fig. 11, the detected volume of gases matches the theoretical one, implying a high Faraday efficiency close to $100 \%$. Moreover, the $\mathrm{Sr}_{2} \mathrm{RuO}_{4}$ oxide 
catalyst prepared by a simple solid-state reaction method enables HER activity comparable to that of the commercial Pt/C catalyst (Supplementary Fig. 12 and Supplementary Fig. 13). Although $\mathrm{Sr}_{2} \mathrm{RuO}_{4}$ still exhibits somewhat lower mass activity than the commercial $\mathrm{Pt} / \mathrm{C}$, it is more advantageous in price activity (Fig. $2 \mathrm{f}$ ) and SA (Supplementary Fig. 14) considering the difference in their price (Supplementary Table 5) and specific surface area. It is also worthwhile to note that $\mathrm{Sr}_{2} \mathrm{RuO}_{4}$ shows much better durability than the benchmark $\mathrm{Pt} / \mathrm{C}$ catalyst, demonstrating its value for practical application (Supplementary Fig. 15). The poor durability of $\mathrm{Pt} / \mathrm{C}$ catalyst may be related to the dissolution of Pt surface atoms, the agglomeration of $\mathrm{Pt}$ particles, and the corrosion of the carbon support $^{31,32}$.

Theoretical study. Clearly, the layered $\mathrm{RP} \mathrm{Sr}_{2} \mathrm{RuO}_{4}$ oxide exhibits significantly higher HER activity than the simple oxide $\mathrm{RuO}_{2}$ and perovskite oxide $\mathrm{SrRuO}_{3}$ in alkaline media. To explore the origin of the high electrocatalytic activity, we resorted to DFT calculations. HER in an alkaline solution that is considered to proceed via two steps $5,8,9,25,28$, i.e., either Volmer-Heyrovsky or Volmer -Tafel pathways (Volmer: ${ }^{\star}+\mathrm{H}_{2} \mathrm{O}+\mathrm{e}^{-} \rightarrow \mathrm{H}^{\star}+\mathrm{OH}^{-}$; Heyrovsky: $\mathrm{H}^{\star}+\mathrm{H}_{2} \mathrm{O}+\mathrm{e}^{-} \rightarrow \mathrm{H}_{2}+\mathrm{OH}^{-}$; Tafel: $\mathrm{H}^{\star}+\mathrm{H}^{\star} \rightarrow \mathrm{H}_{2}$, where $\star$ is the active site). Based on the above analysis of Tafel slope, the three oxides including $\mathrm{Sr}_{2} \mathrm{RuO}_{4}$ underwent a Volmer-Heyrovsky pathway in alkaline media. TMOs are generally regarded as unfavorable catalysts for converting $\mathrm{H}^{*}$ to $\mathrm{H}_{2}$ (either too strong $\mathrm{H}^{\star}$ adsorption on oxygen ion or too weak $\mathrm{H}^{\star}$ adsorption on metal ion $)^{8,9,29,33}$; thus we first studied hydrogen adsorption on the catalysts surface. The adsorption-free energy of $\mathrm{H}^{\star}\left(\Delta G_{\mathrm{H}^{*}}\right)$ is a key descriptor of the HER activity in both alkaline and acidic conditions, and generally a $\Delta G_{\mathrm{H}^{*}}$ value close to zero results in superior HER activity due to the optimal balance between absorption and desorption of hydrogen atoms on the active sites $9,10,28,34,35$. Hence, the $\Delta G_{\mathrm{H}^{*}}$ at the metal site or oxygen $(\mathrm{O})$ site for $\mathrm{RuO}_{2}, \mathrm{SrRuO}_{3}$, and $\mathrm{Sr}_{2} \mathrm{RuO}_{4}$ was calculated using DFT according to the as-built catalyst structural models (Supplementary Fig. 16-18), along with $\mathrm{Ru}$ and $\mathrm{Pt}$ metals as references. Notably, the (001) SrO-terminated surface of $\mathrm{Sr}_{2} \mathrm{RuO}_{4}$, the (010) $\mathrm{RuO}_{2}$-terminated surface of $\mathrm{SrRuO}_{3}$, (110) surface of $\mathrm{RuO}_{2}$, and (0001) surface of $\mathrm{Ru}$ and (111) surface of Pt were used in our theoretical investigation considering that they are among the most usually observed and most stable ones in both experimental and theoretical studies ${ }^{21,28,36-39}$. Besides, based on previous findings that octahedral rotation happens on the surface of $\mathrm{Sr}_{2} \mathrm{RuO}_{4}{ }^{21,40}$, the $\mathrm{RuO}_{6}$ octahedral unit rotated alternatingly by $\sim 8.4^{\circ}$ is also considered (Fig. 3a). Figure $3 \mathrm{~b}$ shows the $\Delta G_{\mathrm{H}^{*}}$ values on all the possible sites for the studied samples. The $\Delta G_{\mathrm{H}^{*}}$ value on $\mathrm{Ru}$ and $\mathrm{O}$ site for $\mathrm{RuO}_{2}$ is 0.48 and $-0.8 \mathrm{eV}$, respectively, indicating that the $\mathrm{H}^{*}$ adsorption is either too weak or too strong. Consequently, the HER kinetics are sluggish on the $\mathrm{RuO}_{2}$ surface. For $\mathrm{SrRuO}_{3}$, the $\mathrm{H}$ binding strength is relatively too strong regardless of whether $\mathrm{H}$ adsorbs on $\mathrm{Ru}$ or $\mathrm{O}$ site, resulting in suppressed $\mathrm{H}$ desorption and $\mathrm{H}_{2}$ production is thus hindered. Impressively, the $\Delta G_{\mathrm{H}^{*}}$ value on the $\mathrm{O}$ site of $\mathrm{Sr}_{2} \mathrm{RuO}_{4}$ is only $-0.08 \mathrm{eV}$, which is most close to ideal zero and very similar to $\mathrm{Pt}$ $(-0.10 \mathrm{eV})$, suggesting an optimum hydrogen adsorption strength on the surface of $\mathrm{Sr}_{2} \mathrm{RuO}_{4}$. The $\mathrm{H}^{\star}$ adsorption ability of transition metal compounds at the nonmetal site has been recently reported to relate to the electronic structure of metal elements (e.g., d-band center) ${ }^{41,42}$ and geometry factors (e.g., bond length) ${ }^{41,43,44}$. Thus, the d-band center of $\mathrm{Ru}$ (Supplementary Fig. 19) and $\mathrm{Ru}-\mathrm{O}$ bond length were calculated for $\mathrm{RuO}_{2}, \mathrm{SrRuO}_{3}$, and $\mathrm{Sr}_{2} \mathrm{RuO}_{4}$ oxides. As seen from Fig. 3c, the $\Delta G_{\mathrm{H}^{*}} @ \mathrm{O}$ value increases as the d-band center downshifts and $\mathrm{Ru}$ $-\mathrm{O}$ bond length increases, which is consistent with previous resports ${ }^{41}$. Especially, $\mathrm{Sr}_{2} \mathrm{RuO}_{4}$ delivers weaker $\mathrm{H}$ adsorption ability resulting from the downshift of the d-band center and the increase of bond length compared to $\mathrm{SrRuO}_{3}$ and $\mathrm{RuO}_{2}$, generating optimal level (close to 0 ) contributing to the highest HER activity. It is worth noting that there are only small variations in the adsorption energies calculated in vacuum and with solvation effects considered (Supplementary Table 6). In addition, the coverage effect of $\mathrm{H}$ on $\Delta G_{\mathrm{H}^{*}}$ for $\mathrm{Sr}_{2} \mathrm{RuO}_{4}$ and $\mathrm{SrRuO}_{3}$ was also considered. The results as shown in Supplementary Fig. 20 support the conclusion that $\mathrm{Sr}_{2} \mathrm{RuO}_{4}$ can achieve higher coverages with lower potentials while the same is not necessarily the case for $\mathrm{SrRuO}_{3}$ as going from low coverage to high coverage involves high potentials $\left(\theta_{\mathrm{H}}=0.25-0.5 \mathrm{ML}\right)$.

Notably, apart from the $\Delta G_{\mathrm{H}^{*}}$ value, the water dissociation kinetics is also very crucial to the overall reaction rate for the alkaline $\operatorname{HER}^{4,8,9,28,35}$, which can be reflected by the activity difference between acidic and alkaline media of $\mathrm{Pt} / \mathrm{C}$ and $\mathrm{Sr}_{2} \mathrm{RuO}_{4}$ catalysts. For benchmark $\mathrm{Pt} / \mathrm{C}$ catalyst, the HER activity in an alkaline solution is lower than that in an acidic solution (Supplementary Fig. 21), indicating sluggish water dissociation in the catalytic process. Nevertheless, judged from the overpotential and TOF, $\mathrm{Sr}_{2} \mathrm{RuO}_{4}$ exhibits higher HER activity in an alkaline solution than in an acidic solution (Supplementary Fig. 22), due likely to faster kinetics for water dissociation, as demonstrated by Diebold et al. using lowtemperature scanning tunneling microscopy $(\mathrm{STM})^{21}$. They found that this layered RP structure easily cleaves apart in the rock-salt layer, and water dissociation is facile on the SrOterminated surface ${ }^{21}$. We further performed DFT calculation of the energies for the water dissociation to demonstrate this phenomenon. To gain a more comprehensive picture about the $\mathrm{H}_{2}$ evolution reaction mechanism, we modeled the complete Volmer-Heyrovsky mechanism occurring at the most stable surfaces of $\mathrm{Sr}_{2} \mathrm{RuO}_{4}$ and $\mathrm{SrRuO}_{3}$. As displayed in Fig. 3d, e, $\mathrm{Sr}_{2} \mathrm{RuO}_{4}$ shows much lower energy barrier for water dissociation as compared with $\mathrm{SrRuO}_{3}$. Strikingly, on the SrO-terminated surface of $\mathrm{Sr}_{2} \mathrm{RuO}_{4}$, the kinetics to split water molecules is very favorable with the first water molecule splitting via a barrierless pathway. For the second water molecule splitting via the Heyrovsky step $\left(\mathrm{H}^{\star}+\mathrm{H}_{2} \mathrm{O}+\mathrm{e}^{-} \rightarrow \mathrm{H}_{2}+^{\star}+\mathrm{OH}^{-}\right)$, the energy barrier is $1.66 \mathrm{eV}$ at $U=0 \mathrm{~V}$ and can drop to $0.84 \mathrm{eV}$ at $U^{\mathrm{SHE}}=$ $0.83 \mathrm{~V}$. In contrast, $\mathrm{SrRuO}_{3}$ presents large barriers for water dissociation on the most stable $\mathrm{RuO}_{2}$-termination surface, in particular for the second water molecule in the Heyrovsky step where the barrier is about $2.6 \mathrm{eV}$ at $U=0 \mathrm{~V}$. The facile water dissociation results in strong hydroxylation on the surface of $\mathrm{Sr}_{2} \mathrm{RuO}_{4}$, which was characterized by X-ray photoelectron spectroscopy (XPS). XPS spectra of O 1s species (Supplementary Fig. 23) and the corresponding deconvolution results (Supplementary Table 7) demonstrate much larger number of $-\mathrm{OH}$ on the surface for $\mathrm{Sr}_{2} \mathrm{RuO}_{4}$. Abundant $-\mathrm{OH}$ on the surface was further confirmed by considering the $\mathrm{Sr} 3 \mathrm{~d}$ spectra of $\mathrm{Sr}_{2} \mathrm{RuO}_{4}$ (Supplementary Fig. 24), and the result shows the formation of hydroxide surface species. Previous studies have proven that (hydro-)oxides can effectively promote the dissociation of water $9,33,45,46$, and thereby it is believed that abundant $-\mathrm{OH}$ specie on the surface of $\mathrm{Sr}_{2} \mathrm{RuO}_{4}$ is beneficial additionally to the water dissociation. Therefore, by theoretical calculations, we reasonably identified the origin of perfect HER performance of the layered $\mathrm{RP} \mathrm{Sr}_{2} \mathrm{RuO}_{4}$ catalyst. Briefly, the outstanding HER catalytic activity in alkaline media of $\mathrm{Sr}_{2} \mathrm{RuO}_{4}$ oxide may be ascribed to an unusual synergistic effect in the RP layered structure, whereby the SrO-terminated surface cleaved in the rock-salt layer promotes water dissociation and the apical oxygen site in the perovskite layer enables favorable hydrogen adsorption for recombination into $\mathrm{H}_{2}$. 
a

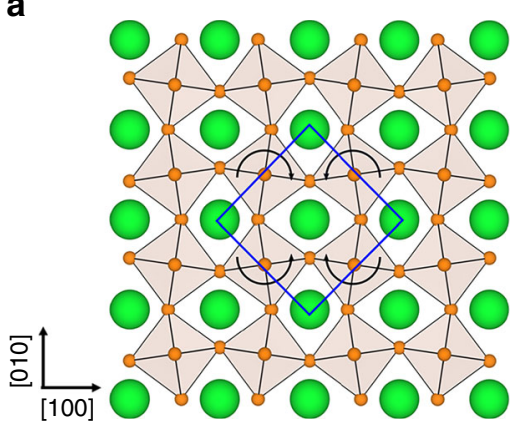

b

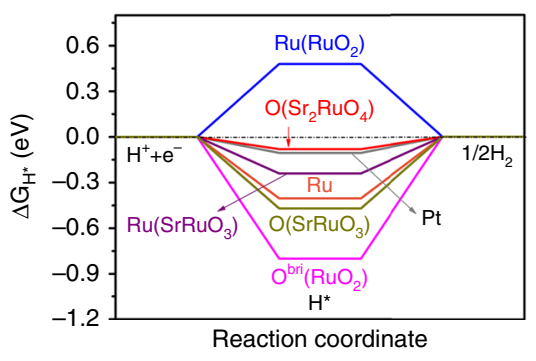

c

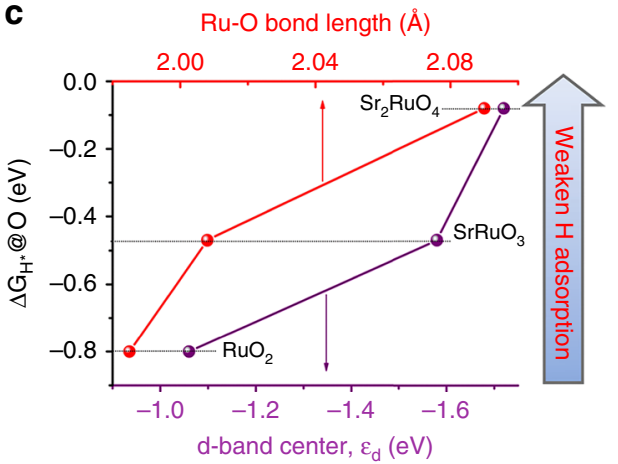

d

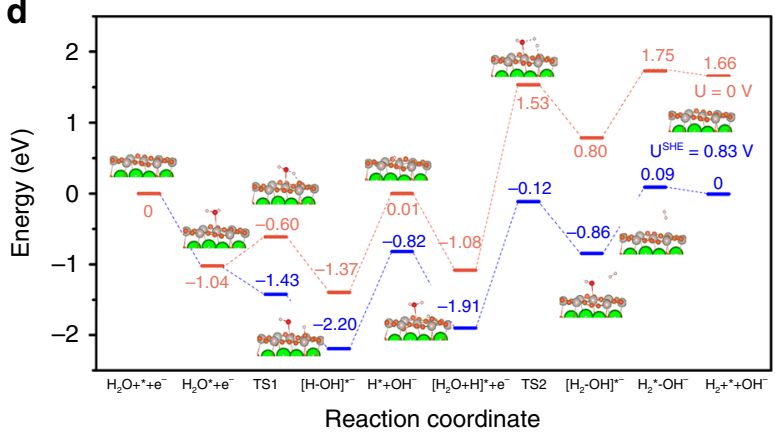

e

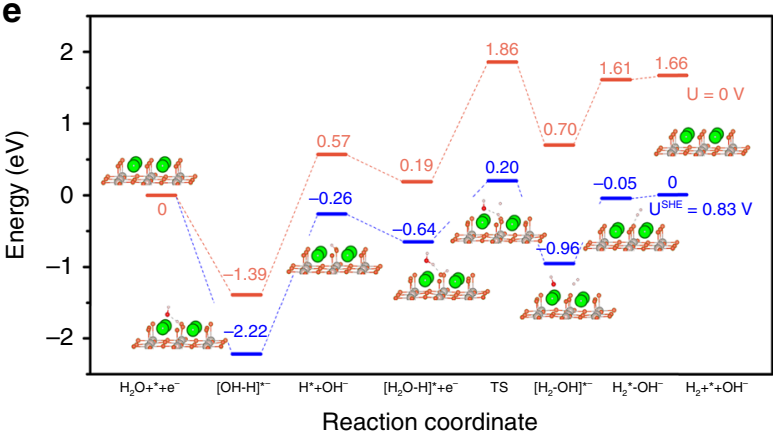

Fig. 3 DFT calculations. a Top view of the SrO-terminated $\mathrm{Sr}_{2} \mathrm{RuO}_{4}(001)$ surface. The $\mathrm{RuO}_{6}$ octahedra are alternately tilted with respect to the $c$-axis, and rotated in the $a b$ plane as indicated by the curved arrows. b Free-energy diagram for hydrogen adsorption at the metal and oxygen sites on $\mathrm{Sr}_{2} \mathrm{RuO}_{4}$, $\mathrm{SrRuO}_{3}, \mathrm{RuO}_{2}, \mathrm{Ru}$, and Pt. c Relationship between $\Delta \mathrm{G}_{\mathrm{H}^{*}} @ \mathrm{O}$ and d-band center as well as Ru-O bond length. Energy diagram and the simplified surface structures of the various reaction species along the Volmer-Heyrovsky pathway for $\mathrm{HER}$ in alkaline media on the $\mathbf{d} \mathrm{RuO}_{2}$-terminated surface of $\mathrm{SrRuO}_{3}$ and $\mathbf{e} \mathrm{SrO}$-terminated surface of $\mathrm{Sr}_{2} \mathrm{RuO}_{4}$ at electrode potential $\mathrm{U}=0 \mathrm{~V}$ and $\mathrm{USHE}^{\mathrm{SHE}}=0.83 \mathrm{~V}$, respectively. TS transition state. The gray, green, orange/red, and light gray spheres represent $\mathrm{Ru}, \mathrm{Sr}, \mathrm{O}$, and $\mathrm{H}$ atoms, respectively

Further activity improvement induced by electrochemical activation. It is interesting to note that the HER activity is further improved after long-term stability test (Supplementary Fig. 15). During the chronopotentiometry test at $-10 \mathrm{~mA} \mathrm{~cm}^{-2}$, the overpotential gradually decreases in the first $\sim 5 \mathrm{~h}$ and then becomes stable during the next $25 \mathrm{~h}$, indicating an activation process with self-improved activity for $\mathrm{Sr}_{2} \mathrm{RuO}_{4}{ }^{47-50}$. The activation process was further verified by accelerated durability test (ADT) with continuous cycling in the HER potential window (Fig. 4a), showing that the overpotential decreases distinctly. To obtain a deeper understanding and to seek the origin of the activation phenomenon during the electrocatalytic process, the $\mathrm{Sr}_{2} \mathrm{RuO}_{4}$ catalyst after ADT of 1000 cycles (denoted as ADT$\mathrm{Sr}_{2} \mathrm{RuO}_{4}$ ) was carefully characterized. Firstly, we checked the change in ECSA of $\mathrm{Sr}_{2} \mathrm{RuO}_{4}$ and $\mathrm{ADT}-\mathrm{Sr}_{2} \mathrm{RuO}_{4}$, which is estimated from the double-layer capacitances by CV method (Supplementary Fig. 8e and Fig. 25). Figure $4 \mathrm{~b}$ displays the current density differences as a function of scan rate of $\mathrm{Sr}_{2} \mathrm{RuO}_{4}$ and ADT- $\mathrm{Sr}_{2} \mathrm{RuO}_{4}$, and the result displays that the ECSA of ADT$\mathrm{Sr}_{2} \mathrm{RuO}_{4}$ is nearly two times larger than that of pristine $\mathrm{Sr}_{2} \mathrm{RuO}_{4}$. The evident increase of ECSA after ADT may be associated with the change in the microstructure and composition of the catalysts ${ }^{47-50}$. The XRD patterns (Fig. 4c) shows that there is no apparent variation in the peak pattern and position between $\mathrm{Sr}_{2} \mathrm{RuO}_{4}$ and ADT- $\mathrm{Sr}_{2} \mathrm{RuO}_{4}$, revealing the unchanged bulk crystal structure of $\mathrm{Sr}_{2} \mathrm{RuO}_{4}$ during ADT. XAS technique was adopted to investigate the surface electronic structure of the transition metal. As displayed in Fig. 4 d, a $0.2-\mathrm{eV}$ shift of $\mathrm{Ru}-L_{2,3}$ edge toward low photo energy was observed for $\mathrm{ADT}-\mathrm{Sr}_{2} \mathrm{RuO}_{4}$ relative to $\mathrm{Sr}_{2} \mathrm{RuO}_{4}$, which implies partial reduction of surface $\mathrm{Ru}^{4+}$. Moreover, the surface morphology was also examined and Supplementary
Fig. 26 shows TEM images of the surface regions of ADT$\mathrm{Sr}_{2} \mathrm{RuO}_{4}$. It is clearly seen that some nanoparticles with a radius of $10-15 \mathrm{~nm}$ are dispersed on the $\mathrm{ADT}-\mathrm{Sr}_{2} \mathrm{RuO}_{4}$ surface. The lattice fringe with lattice space of $0.23 \mathrm{~nm}$ corresponds to the (001) plane of hexagonal Ru, suggesting that these nanoparticles are composed of metallic $\mathrm{Ru}$ in accordance with the XAS result. The high-angle annular dark-field scanning transmission electron microscopy (HAADF-STEM) image (Fig. 4e) together with the energy-dispersive X-ray spectroscopy (EDX) elemental mapping and point spectra (Fig. 4f) further collectively confirm the formation of metallic Ru nanoparticles and oxide on the surface of ADT- $-\mathrm{Sr}_{2} \mathrm{RuO}_{4}$. In conjunction with the above XRD, XAS, TEM, STEM, EDX and electrochemical results, we can conclude that the further-improved activity for $\mathrm{Sr}_{2} \mathrm{RuO}_{4}$ through electrochemical activation mainly originates from the interface synergy between in situ formation of Ru nanoparticle and oxide substrate over the surface $^{51-53}$ as well as increased ECSA. The complete picture of interface synergy between these two components requires a future in-depth work.

\section{Discussion}

In summary, we have demonstrated that that layered $\mathrm{RP} \mathrm{Sr}_{2} \mathrm{RuO}_{4}$ oxide has very high electrocatalytic activity for HER in alkaline media. Remarkably, when evaluated in $1 \mathrm{M} \mathrm{KOH}$ solution, the catalyst exhibits an onset overpotential of only $3 \mathrm{mV}$, low overpotential of $61 \mathrm{mV}$ at $10 \mathrm{~mA} \mathrm{~cm}^{-2}$, low Tafel slope of $51 \mathrm{mV} \mathrm{dec}^{-1}$, large exchange current density of $0.898 \mathrm{~mA} \mathrm{~cm}^{-2}$, and high TOF values (e.g., $0.90 \mathrm{~s}^{-1}$ at overpotential of $100 \mathrm{mV}$ ), which is comparable to a commercial $\mathrm{Pt} / \mathrm{C}$ catalyst and competitive with the best Pt-free electrocatalysts ever reported. Such excellent HER activity of 

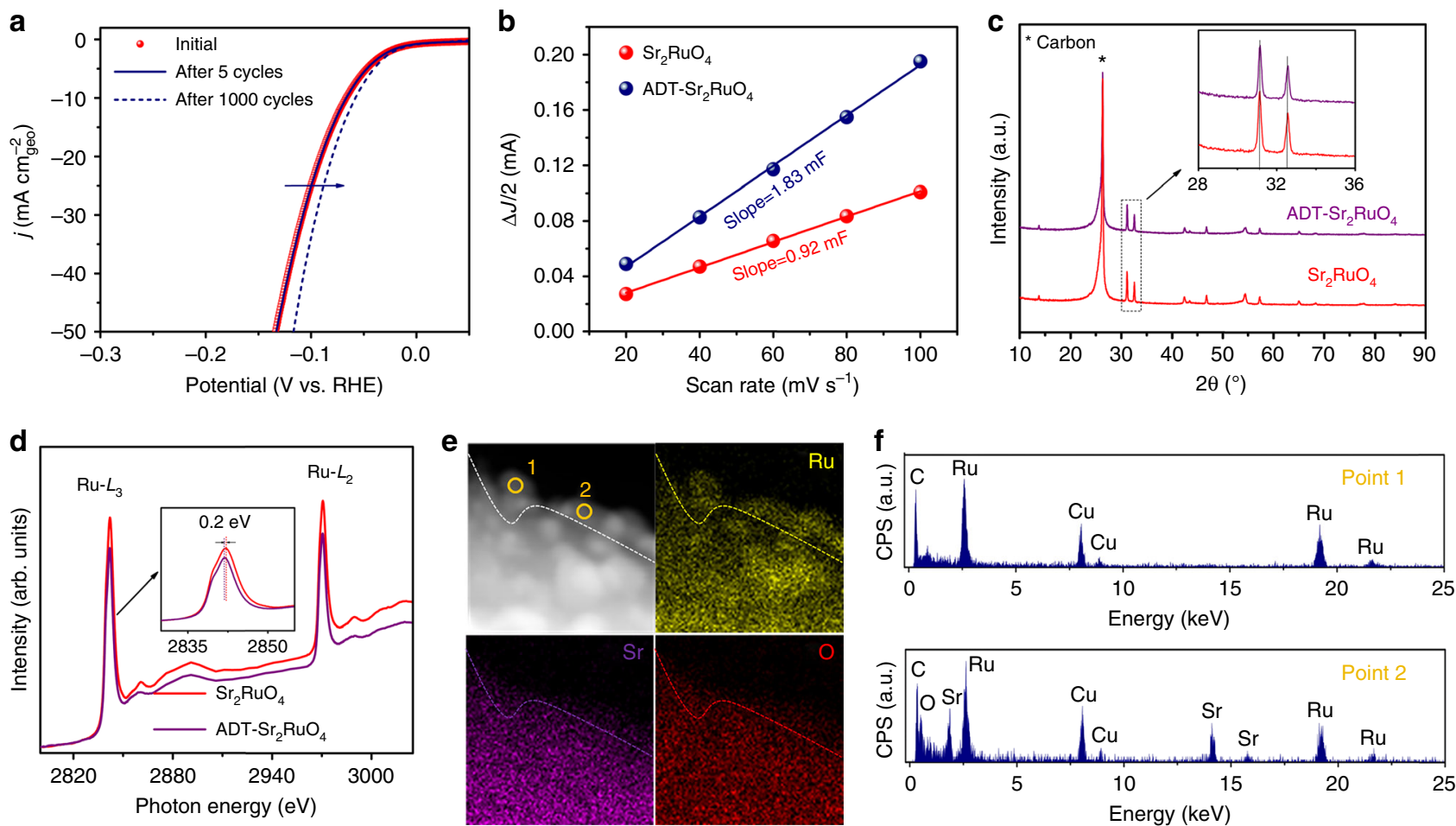

Fig. 4 Electrochemical activation of $\mathrm{Sr}_{2} \mathrm{RuO}_{4}$ by $\mathrm{ADT}$. a Polarization curves of $\mathrm{Sr}_{2} \mathrm{RuO}_{4}$ catalyst initially, as well as after 5 and 1000 cycles. $\mathbf{b}$ Linear fitting curves of the capacitive currents versus $\mathrm{CV}$ scan rates for $\mathrm{Sr}_{2} \mathrm{RuO}_{4}$ and $\mathrm{ADT}-\mathrm{Sr}_{2} \mathrm{RuO}_{4}$. $\mathbf{c}$ XRD patterns of $\mathrm{Sr}_{2} \mathrm{RuO}_{4}$ and $\mathrm{ADT}-\mathrm{Sr}_{2} \mathrm{RuO}_{4}$ loaded on the carbon paper substrate. Insert is the magnified XRD patterns showing main peaks of $\mathrm{Sr}_{2} \mathrm{RuO}_{4}$ and ADT-Sr$r_{2} \mathrm{RuO}_{4}$. d Ru- $L_{2,3} X A S$ spectra of $\mathrm{Sr}_{2} \mathrm{RuO} \mathrm{O}_{4}$ and $A D T-$ $\mathrm{Sr}_{2} \mathrm{RuO}_{4}$. Insert is the magnified $\mathrm{Ru}-L_{3}$ spectra of $\mathrm{Sr}_{2} \mathrm{RuO}_{4}$ and $A D T-\mathrm{Sr}_{2} \mathrm{RuO}_{4}$. e HAADF-STEM image and the corresponding EDX elemental mapping of ADT- $\mathrm{Sr}_{2} \mathrm{RuO}_{4}$. $\mathbf{f}$ EDX spectra at the position in points 1 and 2 in (e)

$\mathrm{Sr}_{2} \mathrm{RuO}_{4}$ is attributed mainly to a synergistic effect associated with the layered RP structure, in which the SrO-terminated surface cleaved the in rock-salt layer promotes water dissociation, and the apical oxygen site in the perovskite layer facilitates favorable hydrogen adsorption, as confirmed by experiments and theoretical calculations. The favorable hydrogen adsorption for $\mathrm{Sr}_{2} \mathrm{RuO}_{4}$ on oxygen site is closely associated with the d-band center of $\mathrm{Ru}$ and $\mathrm{Ru}-\mathrm{O}$ bond length. Moreover, the HER activity of $\mathrm{Sr}_{2} \mathrm{RuO}_{4}$ can be further enhanced by interface synergy between in situ formation of $\mathrm{Ru}$ nanoparticle and oxide substrate over the surface as well as increased active sites during the long-term stability test, which are substantiated by XRD, XAS, TEM, STEM, EDX and electrochemical analysis. This work not only demonstrates a new family of layered $\mathrm{RP} \mathrm{Sr}_{2} \mathrm{RuO}_{4}$ oxide as an efficient HER catalysts, but also opens a new avenue for the development of next-generation high-performance electrocatalysts through unusual synergistic effects in the crystal structure.

\section{Methods}

Catalyst synthesis. The $\mathrm{Sr}_{2} \mathrm{RuO}_{4}$ was synthesized by traditional solid-state reaction route. Taking the synthesis of $\mathrm{Sr}_{2} \mathrm{RuO}_{4}$ as an example, stoichiometric amounts of $\mathrm{SrCO}_{3}$ and $\mathrm{RuO}_{2}$ were weighed and mixed using a high-energy ball mill (Planetary Mono Mill, Pulverisette 6, Fritsch) in ethanol media under $400 \mathrm{rpm}$ for $1 \mathrm{~h}$. The homogeneously dispersed mixture was then dried and calcined at $1200{ }^{\circ} \mathrm{C}$ in air for $20 \mathrm{~h}$ to form the $\mathrm{Sr}_{2} \mathrm{RuO}_{4}$ powders. $\mathrm{SrRuO}_{3}$ was also prepared by the identical procedure as $\mathrm{Sr}_{2} \mathrm{RuO}_{4}$ with the exception of the distinction of raw materials and their contents. The $\mathrm{RuO}_{2}$ powder used in this study was purchased from Alfer Aesar and the commercial Pt/C catalyst was purchased from Johnson Matthey Company.

Basic characterizations. The crystal structure of the as-prepared powders was studied by room temperature XRD (Rigaku Smartlab) using filtered $\mathrm{Cu}-\mathrm{Ka}$ radiation $(\lambda=1.5418 \AA$ ) at a tube voltage of $40 \mathrm{kV}$ and current of $40 \mathrm{~mA}$. XRD patterns were collected by step scanning with an interval of $0.02^{\circ}$ in the $2 \theta$ range of $10-90^{\circ}$. More detailed structural information (e.g., the space group and lattice parameters) was attained by Rietveld refinements using the GSAS-EXPGUI package. HRTEM images and the corresponding SAED patterns were obtained on a transmission election microscope (TEM, FEI Tecnai G2T20) at an accelerating voltage of $300 \mathrm{kV}$. HAADF-STEM images along with the corresponding EDX compositional line profiles were attained on a field-emission transmission electron microscope (FEI Tecnai G2 F30 STWIN) equipped with an EDX analyzer at 200 $\mathrm{kV}$. SEM images were obtained using a Hitachi S-4800 scanning electron microanalyzer. Nitrogen adsorption isotherms were tested under 77 K (BELSORP II) and the specific surface areas were calculated by the BET methods. An Agilent (7820 A) gas chromatography system equipped with an HP-plot molecular sieve ( $5 \AA$ ) column and a thermal conductivity detector was employed to obtain gas chromatography data. Hydrogen was detected using a long ( $24 \mathrm{~m}$ length) column with a nitrogen carrier gas. The surface element states were probed using an XPS

(PHI5000 VersaProbe equipped with an Al Ka X-ray source) and public XPSPEAK software package was used to fit the obtained data. The synchrotron-based measurements were carried out using the soft X-ray spectroscopy beamline at the Taiwan Synchrotron. The Ru- $L_{3}$ XAS spectra were measured in the total-electronyield mode. Ru- $L_{3}$ XAS spectra of $\mathrm{Ru}$-based standard references $\left(\mathrm{RuCl}_{3}, \mathrm{Sr}_{2} \mathrm{RuO}_{4}\right.$, and $\mathrm{Sr}_{2} \mathrm{GdRuO}_{6}$ ) were collected under the same conditions.

Electrode preparation. Working electrodes for HER measurements were prepared by a controlled drop-casting method including an RDE comprising a glassy carbon (GC) electrode with $0.196 \mathrm{~cm}^{2}$ (Pine Research Instrumentation), which was prepolished with aqueous alumina suspension. To eliminate the electrode conductivity restriction within thin film working electrodes, the catalysts in this study were mixed with as-obtained conductive carbon (Super P Li) at a 1:1 mass ratio. Briefly, a $5 \mu \mathrm{L}$ aliquot of the catalyst ink, which was prepared by sonication of a mixture of $10 \mathrm{mg}$ of oxide powder and $10 \mathrm{mg}$ of conductive carbon dispersed in $1 \mathrm{~mL}$ ethanol and $100 \mu \mathrm{L}$ of $5 \mathrm{wt} \%$ Nafion solution for at least $1 \mathrm{~h}$, was dropped on the GC surface, generating an approximate catalyst loading of $0.464 \mathrm{mg}_{\text {total }} \mathrm{cm}^{-2}(0.232$ $\mathrm{mg}_{\text {oxide }} \mathrm{cm}^{-2}$ ) and was left to dry before the electrochemical tests. Working electrode containing commercial $20 \mathrm{wt} \% \mathrm{Pt} / \mathrm{C}$ catalyst was prepared according to the following procedures. Ten milligrams $\mathrm{Pt} / \mathrm{C}$ and $100 \mu \mathrm{L}$ of $5 \mathrm{wt} \%$ Nafion solution were ultrasonically dispersed in $1 \mathrm{~mL}$ of ethanol to form a homogeneous ink. Five microliters of the homogeneous ink was transferred onto the surface of the GC substrate, generating an approximate catalyst loading of $0.232 \mathrm{mg}_{\text {total }} \mathrm{cm}^{-2}(0.0464$ $\left.\mathrm{mg}_{\mathrm{Pt}} \mathrm{cm}^{-2}\right)$. 
Electrochemical measurements. HER performance of catalysts in alkaline or acidic solutions was assessed on a $\mathrm{CHI} 760 \mathrm{D}$ electrochemistry workstation at room temperature in a standard three-electrode electrochemical cell (Pine Research Instrumentation) in an RDE configuration. Catalysts cast on RDE, graphite rod and $\mathrm{Ag} \mid \mathrm{AgCl}(3.5 \mathrm{M} \mathrm{KCl})$ were used as the working electrode, counter electrode, and reference electrode, respectively. Throughout the measurement, the RDE electrode was rotated at $1600 \mathrm{rpm}$ to remove the bubbles formed at the electrode surface. The electrolyte solution was bubbled with Ar for $~ 30$ min before HER tests and maintained under Ar atmosphere during the test period. HER polarization curves were recorded from -0.8 to $-1.6 \mathrm{~V}$ vs. $\mathrm{Ag} \mid \mathrm{AgCl}$ in $1 \mathrm{M} \mathrm{KOH}$ solutions and from 0 to $-0.6 \mathrm{~V}$ vs. $\mathrm{Ag} \mid \mathrm{AgCl}$ in $0.5 \mathrm{H}_{2} \mathrm{SO}_{4}$ solutions. IR compensation for all polarization curves in this study was performed unless noted otherwise. Tafel plots were obtained by replotting the polarization curves as overpotential $(\eta)$ versus the logarithm of current density $(\log |J|)$. Extrapolating the Tafel plots to the overpotential of $0 \mathrm{~V}$ to attain the exchange current density $\left(j_{0}\right)$. Accelerated durability tests of catalysts were conducted through continuous potential cycling ranged from -0.8 to $-1.4 \mathrm{~V}$ vs. $\mathrm{Ag} \mid \mathrm{AgCl}$ for 1000 cycles at a scan rate of $100 \mathrm{mV} \mathrm{s}^{-1}$. The chronopotentiometry tests were performed at a constant cathodic current density of $10 \mathrm{~mA} \mathrm{~cm}^{-2}$. CV tests were conducted in the potential range between -0.8 and $-0.9 \mathrm{~V}$ vs. $\mathrm{Ag} \mid \mathrm{AgCl}$ (where no faradic current was observed) with different sweeping rates of $20,40,60,80$, and $100 \mathrm{mV} \mathrm{s}^{-1}$ to measure the electrochemical double-layer capacitance $\left(C_{\mathrm{dl}}\right)$. The slopes obtained from the plots as the halves of the positive and negative current density differences at the center of the scanning potential range (i.e., $-0.85 \mathrm{~V}$ ) versus scan rates are the $C_{\mathrm{dl}}$ values.

Computational methods. Electronic structure calculations were performed using the Vienna ab initio Simulation Package (VASP) $)^{54,55}$. Exchange and correlation were described using the generalized gradient approximation with the Perdew - Burke-Ernzerhof functional ${ }^{56}$. The projector augmented wavefunction method ${ }^{57}$ was used to describe pseudopotentials. Van der Waals correction was employed in all calculations ${ }^{58}$. A kinetic energy cut-off of $500 \mathrm{eV}$ was used. Uni cells of $\mathrm{Ru}, \mathrm{Pt}, \mathrm{RuO}_{2}, \mathrm{SrRuO}_{3}$, and $\mathrm{Sr}_{2} \mathrm{RuO}_{4}$ were fully relaxed, and the resulting structures were cleaved to construct symmetric slabs which were sandwiched in about $20 \AA$ of vacuum. Hydrogen adsorption was investigated by placing $\mathrm{H}$ on various sites on the metal and oxides surfaces, and the binding energy was calculated as:

$$
\Delta E_{\mathrm{H}}=E_{\mathrm{H}^{*}}-E_{\text {bare }}-1 / 2 E_{\mathrm{H}_{2}},
$$

where $E_{\mathrm{H} *}, E_{\mathrm{bare}}$, and $E_{\mathrm{H}_{2}}$ are the total energies of an adsorbed hydrogen, the bare surface and the energy of a hydrogen molecule, respectively. Free energies $\Delta G_{\mathrm{H}^{*}}$, were obtained by adding the zero-point energy (ZPE) and entropic correction to the binding energy such as $\Delta G_{\mathrm{H}^{*}}=\Delta E_{\mathrm{H}}+\Delta E_{\mathrm{ZPE}}-T \Delta S$. The total correction $\Delta E_{\mathrm{ZPE}}-T \Delta S$ was estimated to be $0.24 \mathrm{eV}$ for metals and oxides and this value is used consistently throughout ${ }^{59}$. Metal d-band centers were determined by evaluating the centroid of the projected DOS including valence and conduction states relative to the Fermi level. Water dissociation barriers were calculated using the climbing image nudged elastic band ${ }^{60}$ (CI-NEB) using five images and a force tolerance of $0.02 \mathrm{eV} / \AA \AA$. The Volmer-Heyrovsky pathway of HER in alkaline media $\left(2 \mathrm{H}_{2} \mathrm{O}+2 \mathrm{e}^{-} \rightarrow \mathrm{H}_{2}+2 \mathrm{OH}^{-}\right)$proceeds through two electrochemical elementary steps and two electrons involved $\left(\mathrm{H}_{2} \mathrm{O}+{ }^{*}+\mathrm{e}^{-} \rightarrow \mathrm{H}^{*}+\mathrm{OH}^{-} ; \mathrm{H}^{*}+\mathrm{H}_{2} \mathrm{O}+\mathrm{e}^{-} \rightarrow\right.$ $\mathrm{H}_{2}+^{*}+\mathrm{OH}^{-}$; where the ${ }^{*}$ denotes the catalyst surface). The effect of $\mathrm{pH}$ can be accounted for within the computational hydrogen electrode formalism by including the changes due to $k_{\mathrm{B}} T \ln 10^{\star} \mathrm{pH}\left(k_{\mathrm{B}}\right.$ is Boltzmann's constant) for which the chemical potential for $\mathrm{H}^{+}+\mathrm{e}^{-}=1 / 2 \mathrm{H}_{2}-k_{\mathrm{B}} T \ln 10^{*} \mathrm{pH}$. A pH $=14$ corresponding to fully alkaline conditions results in an equilibrium potential of $0.83 \mathrm{~V}$. The energy of $G\left(\mathrm{OH}^{-}\right)$can be obtained from $G\left(\mathrm{H}_{2} \mathrm{O}\right)$ and $G\left(\mathrm{H}^{+}\right)$via $G$ $\left(\mathrm{OH}^{-}\right)=G\left(\mathrm{H}_{2} \mathrm{O}\right)-G\left(\mathrm{H}^{+}\right)=G\left(\mathrm{H}_{2} \mathrm{O}\right)-G\left(1 / 2 \mathrm{H}_{2}\right)+k_{\mathrm{B}} T \ln 10^{\star} \mathrm{pH}^{41}$.

\section{Data availability}

The data that support the findings of this study are available from the corresponding authors upon request.

Received: 14 April 2018 Accepted: 17 December 2018

Published online: 11 January 2019

\section{References}

1. Chu, S. \& Majumdar, A. Opportunities and challenges for a sustainable energy future. Nature 488, 294-303 (2012).

2. Turner, J. A. Sustainable hydrogen production. Science 305, 972-974 (2004).

3. Zou, X. \& Zhang, Y. Noble metal-free hydrogen evolution catalysts for water splitting. Chem. Soc. Rev. 44, 5148-5180 (2015).

4. Zeng, K. \& Zhang, D. Recent progress in alkaline water electrolysis for hydrogen production and applications. Prog. Energy Combust. Sci. 36, 307-326 (2010).
5. Zhu, Y. et al. A perovskite nanorod as bifunctional electrocatalyst for overall water splitting. Adv. Energy Mater. 7, 1602122 (2017).

6. Durst, J. et al. New insights into the electrochemical hydrogen oxidation and evolution reaction mechanism. Energy Environ. Sci. 7, 2250-2260 (2014).

7. Wu, R., Zhang, J., Shi, Y., Liu, D. \& Zhang, B. Metallic $\mathrm{WO}_{2}$-carbon mesoporous nanowires as highly efficient electrocatalysts for hydrogen evolution reaction. J. Am. Chem. Soc. 137, 6983-6986 (2015).

8. Ling, T. et al. Activating cobalt (II) oxide nanorods for efficient electrocatalysis by strain engineering. Nat. Commun. 8, 1509 (2017).

9. Gong, M. et al. Nanoscale nickel oxide/nickel heterostructures for active hydrogen evolution electrocatalysis. Nat. Commun. 5, 4695 (2014).

10. Zheng, T. et al. Conductive tungsten oxide nanosheets for highly efficient hydrogen evolution. Nano Lett. 17, 7968-7973 (2017).

11. Spataru, N., Le Helloco, J. G. \& Durand, R. A study of $\mathrm{RuO}_{2}$ as an electrocatalyst for hydrogen evolution in alkaline solution. J. Appl. Electrochem. 26, 397-402 (1996).

12. Kötz, E. R. \& Stucki, S. Ruthenium dioxide as a hydrogen-evolving cathode. J. Appl. Electrochem. 17, 1190-1197 (1987).

13. Luo, Z. et al. Mesoporous $\mathrm{MoO}_{3-\mathrm{x}}$ material as an efficient electrocatalyst for hydrogen evolution reactions. Adv. Energy Mater. 6, 1600528 (2016).

14. Wang, $\mathrm{H}$. et al. Bifunctional non-noble metal oxide nanoparticle electrocatalysts through lithium-induced conversion for overall water splitting. Nat. Commun. 6, 7261 (2015)

15. Maeno, Y. et al. Superconductivity in a layered perovskite without copper. Nature 372, 532-534 (1994).

16. Seitz., L. C. et al. A highly active and stable $\mathrm{IrO}_{\mathrm{X}} / \mathrm{SrIrO}_{3}$ catalyst for the oxygen evolution reaction. Science 353, 1011-1014 (2016).

17. Zhu, Y., Zhou, W. \& Shao, Z. Perovskite/carbon composites: applications in oxygen electrocatalysis. Small 13, 1603793 (2017).

18. Bak, J., Bae, H. B., Kim, J., Oh, J. \& Chung, S. Y. Formation of twodimensional homologous faults and oxygen electrocatalytic activities in a perovskite nickelate. Nano Lett. 17, 3126-3132 (2017)

19. Goodenough, J. Electronic and ionic transport properties and other physical aspects of perovskites. Rep. Prog. Phys. 67, 1915-1993 (2004).

20. Du, J. et al. Nonstoichiometric perovskite $\mathrm{CaMnO}_{3-\delta}$ for oxygen electrocatalysis with high activity. Inorg. Chem. 53, 9106-9114 (2014).

21. Halwidl, D. et al. Adsorption of water at the $\mathrm{SrO}$ surface of ruthenates. Nat. Mater. 15, 450-455 (2016).

22. Suntivich, J., May, K. J., Gasteiger, H. A., Goodenough, J. B. \& Shao-Horn, Y A perovskite oxide optimized for oxygen evolution catalysis from molecular orbital principles. Science 334, 1383-1385 (2011).

23. Suntivich, J., Gasteiger, H. A., Yabuuchi, N. \& Shao-Horn, Y. Electrocatalytic measurement methodology of oxide catalysts using a thin-film rotating disk electrode. J. Electrochem. Soc. 157, B1263-B1268 (2010).

24. $\mathrm{Zhu}, \mathrm{Y}$. et al. $\mathrm{SrNb}_{0 \cdot 1} \mathrm{Co}_{0.7} \mathrm{Fe}_{0 \cdot 2} \mathrm{O}_{3-\delta}$ perovskite as a next-generation electrocatalyst for oxygen evolution in alkaline solution. Angew. Chem. Int. Ed. 54, 3897-3901 (2015).

25. Xu, X. et al. A perovskite electrocatalyst for efficient hydrogen evolution reaction. Adv. Mater. 28, 6442-6448 (2016).

26. Miao, R. et al. Mesoporous iron sulfide for highly efficient electrocatalytic hydrogen evolution. J. Am. Chem. Soc. 139, 13604-13607 (2017).

27. Seh, Z. W. et al. Combining theory and experiment in electrocatalysis: Insights into materials design. Science 355, eaad4998 (2017).

28. Zheng, Y. et al. High electrocatalytic hydrogen evolution activity of an anomalous ruthenium catalyst. J. Am. Chem. Soc. 138, 16174-16181 (2016).

29. Kibsgaard, J. \& Jaramillo, T. F. Molybdenum phosphosulfide: an active, acidstable, earth-abundant catalyst for the hydrogen evolution reaction. Angew. Chem. Int. Ed. 53, 14433-14437 (2014)

30. Kibsgaard, J. et al. Designing an improved transition metal phosphide catalyst for hydrogen evolution using experimental and theoretical trends. Energy Environ. Sci. 8, 3022-3029 (2015).

31. Cao, X. et al. Highly catalytic active PtNiCu nanochains for hydrogen evolution reaction. Nano Energy 9, 301-308 (2014).

32. Katsounaros, I., Cherevko, S., Zeradjanin, A. R. \& Mayrhofer, K. J. J. Angew. Chem. Int. Ed. 53, 102-121 (2014).

33. Subbaraman, R. et al. Enhancing hydrogen evolution activity in water splitting by tailoring $\mathrm{Li}+\mathrm{-Ni}(\mathrm{OH})_{2}-\mathrm{Pt}$ interfaces. Science 334, 1256-1260 (2011).

34. Zheng, Y. et al. Hydrogen evolution by a metal-free electrocatalyst. Nat. Commun. 5, 3783 (2014).

35. Su, J. et al. Ruthenium-cobalt nanoalloys encapsulated in nitrogen-doped graphene as active electrocatalysts for producing hydrogen in alkaline media. Nat. Commun. 8, 14969 (2017).

36. Nørskov, J. K., Rossmeisl, J., Logadottir, A. \& Lindqvist, L. Origin of the overpotential for oxygen reduction at a fuel-cell cathode. J. Phys. Chem. B 108 , 17886-17892 (2004)

37. Feibelman, P. J. Partial dissociation of water on Ru (0001). Science $\mathbf{2 9 5}$ 99-102 (2002). 
38. Stoerzinger, K. A., Qiao, L., Biegalski, M. D. \& Shao-Horn, Y. Orientationdependent oxygen evolution activities of rutile $\mathrm{IrO}_{2}$ and $\mathrm{RuO}_{2}$. J. Phys. Chem. Lett. 5, 1636-1641 (2014).

39. Chang, S. H. et al. Hydrogen functional links between stability and reactivity of strontium ruthenate single crystals during oxygen evolution. Nat. Commun. 5, 4191 (2014).

40. Matzdorf, R. et al. Ferromagnetism stabilized by lattice distortion at the surface of the p-wave superconductor $\mathrm{Sr}_{2} \mathrm{RuO}_{4}$. Science 289, 746-748 (2000).

41. $\mathrm{Wu}, \mathrm{Y}$. et al. Electron density modulation of $\mathrm{NiCo}_{2} \mathrm{~S}_{4}$ nanowires by nitrogen incorporation for highly efficient hydrogen evolution catalysis. Nat. Commun. 9, 1425 (2018).

42. Tsai, C., Chan, K., Abild-Pedersen, F. \& Nørskov, J. K. Active edge sites in $\mathrm{MoSe}_{2}$ and $\mathrm{WSe}_{2}$ catalysts for the hydrogen evolution reaction: a density functional study. Phys. Chem. Chem. Phys. 16, 13156-13164 (2014)

43. Chen, G. et al. Efficient and stable bifunctional electrocatalysts $\mathrm{Ni} / \mathrm{NixMy}$ $(\mathrm{M}=\mathrm{P}, \mathrm{S})$ for overall water splitting. Adv. Funct. Mater. 26, 3314-3323 (2016).

44. Laursen, J. et al. Nanocrystalline $\mathrm{Ni}_{5} \mathrm{P}_{4}$ : a hydrogen evolution electrocatalyst of exceptional efficiency in both alkaline and acidic media. Energy Environ. Sci. 8, 1027-1034 (2015)

45. Danilovic, N. et al. Enhancing the alkaline hydrogen evolution reaction activity through the bifunctionality of $\mathrm{Ni}(\mathrm{OH})_{2} /$ metal catalysts. Angew. Chem. Int. Ed. 51, 12495-12498 (2012).

46. Zhu, Y. et al. Synergistically enhanced hydrogen evolution electrocatalysis by in situ exsolution of metallic nanoparticles on perovskites. J. Mater. Chem. A 6, 13582-13587 (2018).

47. $\mathrm{Hu}, \mathrm{C}$. et al. In situ electrochemical production of ultrathin nickel nanosheets for hydrogen evolution electrocatalysis. Chem 3, 122-133 (2017)

48. Zhu, Y., Zhou, W., Sunarso, J., Zhong, Y. \& Shao, Z. Phosphorus-doped perovskite oxide as highly efficient water oxidation electrocatalyst in alkaline solution. Adv. Funct. Mater. 26, 5862-5872 (2016).

49. Yang, C. et al. In-situ activation of self-supported 3D hierarchically porous $\mathrm{Ni}_{3} \mathrm{~S}_{2}$ films grown on nanoporous copper as excellent $\mathrm{pH}$-universal electrocatalysts for hydrogen evolution reaction. Nano Energy 36, 85-94 (2017).

50. Li, Q., Xing, Z., Wang, D., Sun, X. \& Yang, X. In situ electrochemically activated CoMn-S@NiO/CC nanosheets array for enhanced hydrogen evolution. ACS Catal. 6, 2797-2801 (2016).

51. Jiang, P. et al. Pt-like electrocatalytic behavior of $\mathrm{Ru}-\mathrm{MoO}_{2}$ nanocomposites for the hydrogen evolution reaction. J. Mater. Chem. A 5, 5475-5485 (2017).

52. Yoon, D. et al. Cactus-like hollow $\mathrm{Cu}_{2-\mathrm{x}} \mathrm{S} @ \mathrm{Ru}$ nanoplates as excellent and robust electrocatalysts for the alkaline hydrogen evolution reaction. Small 13, 1700052 (2017).

53. $\mathrm{Xu}, \mathrm{J}$. et al. Boosting the hydrogen evolution performance of ruthenium clusters through synergistic coupling with cobalt phosphides. Energy Environ. Sci. 11, 1819-1827 (2018).

54. Kresse, G. \& Furthmüller, J. Efficient iterative schemes for ab initio totalenergy calculations using a plane-wave basis set. Phys. Rev. B 54, 11169 (1996).

55. Kresse, G. \& Furthmüller, J. Efficiency of ab-initio total energy calculations for metals and semiconductors using a plane-wave basis set. Comp. Mater. Sci. 6, 15-50 (1996).

56. Perdew, J. P., Burke, K. \& Ernzerhof, M. Generalized gradient approximation made simple. Phys. Rev. Lett. 77, 3865 (1996).

57. Blöchl, P. E. Projector augmented-wave method. Phys. Rev. B 50, 17953 (1994).

58. Grimme, S. Semiempirical GGA-type density functional constructed with a long-range dispersion correction. J. Comput. Chem. 27, 1787-1799 (2006).
59. Nørskov, J. K. et al. Trends in the exchange current for hydrogen evolution. J. Electrochem. Soc. 152, J23-J26 (2005).

60. Henkelman, G. et al. A climbing image nudged elastic band method for finding saddle points and minimum energy paths. Chem. Phys. 113, 9901 (2000).

\section{Acknowledgements}

This work was financially supported by the National Nature Science Foundation of China under contract No. 21576135, the Priority Academic Program Development of Jiangsu Higher Education Institutions (PAPD), the Major Project of Educational Commission of Jiangsu Province of China under contract No. 13KJA430004, the Program for Jiangsu Specially-Appointed Professors, and the Youth Fund in Jiangsu Province under contract No. BK20150945. Computational work was supported by resources provided by the Pawsey Supercomputing Centre with funding from the Australian Government and the Government of Western Australia.

\section{Author contributions}

Z.S. and Y.Z. conceived and designed the research. Y.Z. conducted characterizations and electrochemical measurements. H.A.T. and S.C.S. performed DFT calculations. Z.H. and H.S. performed XAS characterization. Y.C. performed XRD refinements. J.D. and W.Z. were involved in the structural and electrochemical analysis. All authors discussed and analyzed the data. Y.Z., W.Z., M.L., H.W. and Z.S. co-wrote the manuscript.

\section{Additional information}

Supplementary Information accompanies this paper at https://doi.org/10.1038/s41467 018-08117-6.

Competing interests: The authors declare no competing interests.

Reprints and permission information is available online at http://npg.nature.com/ reprintsandpermissions/

Journal peer review information: Nature Communications thanks the anonymous reviewers for their contributions to the peer review of this work. Peer Reviewer Reports are available.

Publisher's note: Springer Nature remains neutral with regard to jurisdictional claims in published maps and institutional affiliations.

Open Access This article is licensed under a Creative Commons Attribution 4.0 International License, which permits use, sharing, adaptation, distribution and reproduction in any medium or format, as long as you give appropriate credit to the original author(s) and the source, provide a link to the Creative Commons license, and indicate if changes were made. The images or other third party material in this article are included in the article's Creative Commons license, unless indicated otherwise in a credit line to the material. If material is not included in the article's Creative Commons license and your intended use is not permitted by statutory regulation or exceeds the permitted use, you will need to obtain permission directly from the copyright holder. To view a copy of this license, visit http://creativecommons.org/ licenses/by/4.0/.

(c) The Author(s) 2019 